|| ISSN(online): 2589-8698 || ISSN(print): 2589-868X ||

International Journal of Medical and Biomedical Studies

Available Online at www.ijmbs.info

NLM (National Library of Medicine ID: 101738825)

Index Copernicus Value 2019: 79.34

Systematic Review

Volume 5, Issue 5; May: 2021; Page No. 64-83

\title{
REVIEWING ISOLATION AND PRODUCTION OF PROBIOTICS
}

\author{
Blessy Ponnachan $^{1}$, Neelotpala Dash ${ }^{2}$, Pratiksha Jaybhay ${ }^{3}$, Riya Tiwari ${ }^{4}$
}

${ }^{1}$ St. Joseph's College, Bangalore University,

${ }^{2}$ KIIT Deemed to be University,

${ }^{3}$ Department of Microbiology, Modern College of Arts, Science and Commerce, Pune,

${ }^{4}$ Maitreyi College, University of Delhi

Article Info: Received 13 March 2021; Accepted 18 May 2021

DOI: https://doi.org/10.32553/ijmbs.v5i5.1920

Corresponding author: Blessy Ponnachan, Neelotpala Dash, Pratiksha Jaybhay, Riya Tiwari

Conflict of interest: No conflict of interest.

\begin{abstract}
This article is an examination of the isolation of probiotics The scientific development and subsequent "production of probiotics" continues to influence the researchers all over the globe today. This article examines the research done and published by researchers and scientists. Consideration of current trends and data in scientific queries and demonstrates further aspects of isolation of microbes and probiotics. Additionally, this article explores options for microencapsulation, Bacteriocin production, Aquaculture Probiotics, Yeast production, Antioxidant Probiotic from squid production.
\end{abstract}

Keywords: Microencapsulation, Probiotics, Aquaculture Probiotics, Yeast Production, Isolation Probiotic

\section{Introduction:}

For years now the immediate resort to cure diseases has been antibiotics. The point to focus on is the mutating bacteria which are now resistant to the medicine administered. For a brief period of time the researchers have been working with probiotics to see its effect on humans, and the aquaculture industry. Probiotics on being administered with fermented food and dairy products to humans enhance the good bacteria in the gut hence providing immunity.

The major look out was to gather more understanding about isolation and production techniques of probiotics. With increasing population there is an increasing demand for nutritional food at a lower production cost and that was achieved by using cheese whey as a growth medium for lactic acid bacteria which will give us the probiotic incorporated food as the end result. Microencapsulation technique has been used to avoid any effect on probiotics due to differing $\mathrm{pH}$. The similar microencapsulation technique was used in the aquaculture industry as fishes have to be fed with probiotics to induce immune response to the pathogens.

Various experiments have been conducted to understand whether the probiotic is able to provide protection to the host from pathogens. B. pumilus acts as a promising probiotic bacterium in controlling the pathogenic effect of A. hydrophila in aquaculture. Similarly a study was conducted on probiotic products from whom the bacteria were isolated and tested for antibiotic susceptibility.

The isolation and production strategies used for various probiotics can be of help to genetically engineer probiotics depending on the need of the hour. Very little is known of the way probiotics can heal human's diseases or any other species too without probiotic getting altered by itself. Moving forward the search is for designing probiotics of specific need for any species to confer dominance over harmful pathogens.

\section{Methods:}

The study was conducted using four databases Google Scholars SAGE, DOAJ and PubMed. Selection of papers was done based on keywords and themes relevant to this review. Further the published papers from these databases were arranged in systematic order with respect to the year of publication.

\section{Results and discussion:}

\section{Microencapsulation of probiotic bacteria}

In recent times there has been extreme awareness with regard to the benefits of probiotic bacteria. This led to the production of various products incorporating Lactobacillus species. The products need a protecting cover to preserve its viability and stability. From the known idea of immobilization it leads to the encapsulation technique of the cell.

Immobilization and encapsulation are different terminologies though they are used interchangeably. Encapsulation works with forming a continuous outer surface in the inner matrix where in immobilization it's for the entire cell. Microcapsule is a semipermeable, thin, spherical and strong membranous wall. Microencapsulation protects the core material until released and later on is 
released in a controlled manner. Microencapsulation holds multiple advantages over immobilization.

\section{Methods of encapsulation}

1) Spray drying- core mixed with polymer solution forming a dispersion which is homogenized and is put in a drying chamber for atomization. Advantage being it can be produced continuously and is readily available. Disadvantage being, inlet temperature increases and outlet temperature increases too resulting in reducing viability of probiotic bacteria.

2) Extrusion, emulsion and phase separation- In case of extrusion, depending on the requirement of the probiotic it could be subjected to laboratory scale production or multi scale production. In general there is a nozzle outlet where the core material is put and the polymer solution is introduced forming a capsule. Emulsion involves two phase dispersion and hardening and dispersion is forming a homogeneous mixture. The dispersed aqueous droplets are hardened through cooling or adding a gelling agent or through crossing linking in polysaccharide gel. They are washed to remove oil in case of production of low fat food products.

The material used for microencapsulation shouldn't be toxic, should form matrices with probiotic bacteria, excess mass transfer and contamination. This property was fulfilled by calcium-alginate as it didn't even deteriorate the viability of the cell.

\section{Laboratory procedure for microencapsulation}

Emulsification/Interfacial polymerization- this process involves a discontinuous phase i.e. an emulsion of the cell with an aqueous solution and the continuous phase involves organic solvent. The liquid droplet is confiding inside a thin and strong membrane. The use of organic solvent and aqueous solution for emulsion varies depending on the species. When it came to lactic acid bacteria there was leakage of mass so to avoid that there was tests being carried out one of them was adding poly-l-lysine membrane coating of alginate bead followed by liquefaction was reported. The most effective coating found for lactic acid bacteria was alginate-starch liquid core.

There are various techniques used for small sized microencapsulated probiotic bacteria some of them are bench-top capsule generator (electrostatic potential and adjusting magnitude voltage gave small sized microencapsulated probiotic), jet cutter (forms monodisperse beads due to number of cutting wires attached to the rotating cutting tool), Laminar jet break-up technique (13 nozzle system produce monodisperse beads of calcium alginate) and so many more. But the additional step in these is washing as there is oil water based emulsions which don't work well for all products.

There is another system developed which uses aqueous gelling without use of emulsifiers or soil. They give 20 to $100 \mathrm{~mm}$ microcapsules. And during the operation air is replaced by nitrogen gas in the encapsulation vessel hence allowing oxygen sensitive bacteria. All these techniques are essential because some of the bacteria die due to lack of nutrients like oxygen because of uneven sizes of capsules.

Microencapsulation helps the probiotic bacteria in low $\mathrm{pH}$ conditions as noted in case of set yogurt where the environment is acidic but when it came to cheddar cheese due to comparatively higher $\mathrm{pH}$ and different matrix the microencapsulated probiotic bacteria suffered to death.

Amidst this lies the future of probiotic .i.e. nanoencapsulation which will be inclined towards the medical field and will bring about immune responses for desired antibody production in humans. This will require for invivo testing of the nano-encapsulated probiotic bacteria.

\section{Influences of probiotic bacteria on organic acid production by pig caecal bacteria in vitro}

When this particular paper was written the most definite roles of probiotics weren't known. So it began with how short chain fatty acids (SCFA) provide energy in the colon leading to absorption of $\mathrm{Na}$ and water from the large intestine in diarrhea condition. Acetic acid, propionic acids are SCFA produced as the end product of reduction of carbohydrate. Pigs are used for our study as they resemble in terms of body mass with humans than rodents.

The inoculum was taken from the pig and it was treated with a buffer, was filtered and stored in $4 \mathrm{oC}$ until use. They contained bile acids and mucin just like any other caecal content would have.

For checking the production of SCFA, theoretically we would use radioactive substances for estimation but that would be an expensive process. Fermentation techniques were employed as an alternative. First being batch culture technique, it involved checking dose response between probiotics and host. They used anaerobic buffer and $\mathrm{CO}_{2}$ to maintain anaerobic condition. They do have drawbacks such as exhaustion of substrates and accumulation of fermentation products. Second being continuous culture technique, this technique highlights the time course of the effect. Use of a bicarbonate buffer with autoclaved pig ileal content stabilizes the $\mathrm{pH}$.

The various concentrations of organic acid, $\mathrm{NH}_{4}$, and DNA were estimated via HPLC, photometric method, and optical absorption respectively. The various effects were studied on the production of short chain fatty acids in batch culture, continuous culture, presence of glucose and polypeptone, and presence of starch, lactose and gastric mucin.

The SCFA was produced from probiotic preparation that existed already in the market in a batch culture and was studied for dose response. The digestive enzyme present in the preparation was removed and to do so $\mathrm{HCL}$ and pancreatin were added. These were cultured in $37^{\circ} \mathrm{C}$ for various times span were centrifuged and supernatant was checked for the organic acid, and $\mathrm{NH}_{4}$. There was positive correlation between dose and the SCFA production and 
negative correlation for $\mathrm{NH}_{4}$ and isovaleric acid. Yakult Seichoyaku BL and Yakult Seichoyaku showed an increase in SCFA by breakdown of residual carbohydrate. In addition to glucose there was no increase in SCFA. Hence it was concluded that the presence of digested nutrients allowed probiotics to enhance SCFA production.

The probiotic bacteria were grown in appropriate medium and were checked for growth through hemocytometer. The DNA was checked to the total population size. The carbohydrate source was dietary supplements (Starch and lactose) and gastric mucin belonged to endogenous origin. The supplementation of carbohydrate in the large bowel increased the bacterial population hence enhancing SCFA production. It was seen that probiotic bacteria and additional carbohydrates contributed to increase in acetic acid production to somewhat similar extent.

The probiotic preparation for organic acid production through continuous culture showed that all probiotic preparation showed increase in SCFA production. The carbohydrate breakdown is resistant to indigenous bacteria but these probiotic bacteria enhanced its breakdown for production of organic acid useful to humans.

The genes that enhance these organic acid production through probiotic bacteria can be genetically engineered to produce an effect of interest in humans.

\section{Probiotics in humans - evidence based review}

The presence of microbes in the host implies a benefit on the host. The microbes can be administered to enhance the growth of good bacteria i.e. prebiotic or the good bacteria by itself could be administered for curing the diseases i.e. probiotics. Now the mixture of both prebiotic and probiotic gives symbiotic effect and that's done depending on the need. Immune response produced by probiotics in host has therapeutically strategized in curing various diseases and they were studied.

The gastrointestinal tract is found with microorganisms including Bacteroides, Lactobacillus, Clostridium, Fusobacterium, Bifidobacterium, Eubacterium, Peptococcus, Peptostreptococcus, Escherichia, and Veillonella. New microbes are added to enhance the GIT and the selection of probiotics has criteria to be fulfilled, they need to be isolated from the same species of the host, they should produce antimicrobial effects on encountering pathogens, and should be able to survive the GIT environment.

Western diets as mentioned lack the live microorganisms in food, thus leading to various health issues. The effect of probiotics was studied for various intestinal diseases. Diarrhea is the most common intestinal disease. Diarrhea associated with antibiotic associated, radioactive associated, clostridium difficile diarrhea on reviewing various papers it was seen that probiotics can reduce the occurrence of this diarrhea. Specific probiotic strains were also listed to cure clostridium difficile associated diarrhea. $S$. boulardii was able to prevent disease recurrence.

Inflammatory bowel diseases such as ulcerative colitis, crohn's disease and pouchitis were also seen to be cured with administration of probiotics. Escherichia coli (Nissle), bifidobacteria plus L. acidophilus and VSL\#3 showed prevention of ulcerative colitis.

Lactose intolerance was eliminated with addition of lactobacilli that broke down lactose to glucose and galactose thus helping with digestion of lactose. Probiotics and prebiotics have anti-mutagenic effects but it's not extensively known whether it cures colon cancer or not. Lactulose is prebiotic which is not attacked by human disaccharide, it is a substrate to bifidobacteria and breaks down bigger molecules into smaller molecules hence solving constipation.

Liver diseases such as Hepatic encephalopathy, Nonalcoholic fatty liver disease (NASH) also seemed to be cured due to the properties possessed by probiotics as signal induction seems to cure the disease. Infants gain their probiotics from mother's milk and the consumption of probiotics by mother during pregnancy is the safest during the first 6 months. Probiotics such as Lactobacillus GG cures Necrotizing enterocolitis which is a intestinal disorder. L.acidophilus cures urinary tract infection in women as well as bacterial vaginosis.

These entire listed cures for human diseases paves a way to the advancement of probiotics, depending on the disease associated with the gut the probiotic of choice can be engineered for the desired benefit.

\section{Bacteriocin production as a mechanism for the anti-} infective activity of Lactobacillus salivarius UCC118

Bacteriocin is small peptides that have an antimicrobial activity produced by probiotic bacteria. In this paper the researcher tried to study the role of bacteriocin in eliminating infections caused in humans or animals. The use of antibiotics for curing infection regularly is making them resistant bacteria hence not having any effect in curing the disease.

Lactobacillus salivarius UCC118 produces a class II bacteriocin, Abp118 they provide protection in mice against L. monocytogenes infection that spreads in liver and spleen. L. monocytogenes EGDe and L. monocytogenes LO28 were the 2 strains of L. monocytogenes. They were cultured in Brain heart infusion broth and shaken aerobically at $37 \mathrm{oC}$. $2 \times 109 \mathrm{CFU}$ of $L$. monocytogenes EGDe was given by oral pipette. Before administering $L$. monocytogenes they were given lactobacilli in 1x109 CFU per mouse.

To study the activity of Lactobacillus salivarius UCC118 in mice, bioluminescence was introduced in L. monocytogenes and was studied using Xenogen IVIS 100 system. This was done by infusing hyl promoter to the luxABCDE into the chromosome of $L$. monocytogenes. The dosage of Lactobacillus salivarius almost gave the same effect of 
reduction although the administration 30 mins before oral administration of pathogen caused much greater reduction.

The bacteriocin producing gene was targeted and alerted to mutant form but the growth wasn't altered as much. L.salivarus produced protective effects in the case of $S$. typhimurium. This showed that it was more than mere antiinfection mechanisms, it may be pathogen specific. To rule out the possible function of bacteriocin, as mediating transient colonization or acting as a signaling molecule, a strain of L. monocytogenes was created which was Abp118 resistant on introducing this to L.salivarus they didn't reduce the pathogenic strain.

The dose administered takes very less time to induce a specific host response.

The mutation of bacteria is due to the administered medicines. They are getting resistant to the antibiotics given frequently as a cure. Using probiotics to hamper the working of pathogens and altering the genetic makeup of probiotics with change in probiotics would help humans on a longer run.

\section{Bacteriocin Production: a Probiotic Trait?}

Bacteriocin is produced in the ribosome of probiotic bacteria as antimicrobial peptide which is generally heterogeneous. It's also believed that knowing the genetic makeup of this bacteriocin it can be genetically altered and introduced for better health.

The probiotic produces various antimicrobial compounds to inhibit pathogenic growth such as hydrogen peroxide, nitric oxide, short chain fatty acid, and bacteriocin. The composition of bacteriocin varies depending upon the target cell, mode of action, immunity mechanisms and so much more.

It's known that bacteriocin consumes a lot of energy for production but it's produced anyways due to its benefits on the host. There are 3 main functions associated with bacteriocin that's of great importance to the host. Those are bacteriocin as colonizing peptides, antimicrobial or killing peptide, and signaling peptide.

Colonization of probiotics is an important feature and that's facilitated by bacteriocin produced by various bacteriocin producing probiotic bacteria. Colicin is produced by E.coli and this allowed E.coli to survive is streptomycin treated mice unlike the non colicin producing E.coli. They gain a competitive advantage over the weaker strain and allow survival of bacteriocin producing strain. Even in multispecies and multi-strain probiotics the superior amongst them is attributed to bacteriocin production.

The killing peptide activity of bacteriocin seems to reduce the colonization of pathogens as seen in colicin E7 producing E.coli strain. Studies conducted in vitro didn't have the same effect on entering the host. Like in the case of lacticin 3147 failed to confer protection against Listeria monocytogenes in mouse. But there are cases which showed reduction in vancomycin resistance in vivo. The gram positive bacteria's bacteriocin showed no activity against gram negative pathogens. But gram negative bacteriocins producers seem to have control over pathogens.

Peptides and bacteriocin as signaling molecules are seen in gram positive bacteria but in gram negative bacteria its homoserine lactone. They are extracellular diffusible signaling molecules. Bacteriocin is believed to work as a signaling compound when present in lower concentration. When it comes to peptide they have to component regulatory signal transduction signal, those are histidine protein kinase (HPK) and response regulator (RR). Autoinducing peptide binds to the $\mathrm{N}$ terminal of HPK and causes auto-phosphorylation. The phosphoryl binds to RR thus bringing about an immune response. There are exceptions to these too like Nisin acts as a killing peptide and signaling molecule. It's been identified that $L$. plantarum genes may have an immune response.

There is an unknown factor, as in what causes the production of bacteriocin. On knowing the required details it could come of utmost use to humans for bringing about an immune response of choice by genetically engineering it in vitro.

\section{Use of cheese whey for biomass production and spray} drying of probiotic lactobacilli

With increasing population and demand of food incorporated with probiotic bacteria, it's only logical to think to increase biomass production with decrease in production cost at industrial scale. On coming across with this paper there was an alternate formulated growth media that helped enhance the viability, storage, and most importantly cost reduction.

To achieve this cheese whey is being used as its most abundant wastewater resulting from cheese production and to see how it can act as a thermos-protectant in spray drying technique. Due to its high nutritional value it's been used to act as a nutrient provider to probiotic bacteria. The dried culture is preferred over frozen forms because it helps with long term storage and shipping. Spray drying is one form of drying technique as it's inexpensive and allows continuous batch process.

Lb. paracasei JP1, Lb. rhamnosus 64 and Lb. gasseri 37 were the strains isolated from faeces of neonates. They displayed probiotic properties. They were cultured overnight in MRS (de Man, Rogosa and Sharpe) broth. Formulated broth was obtained from local providers for understanding its capacity for providing growth for the strains of lactobacilli. To avoid protein precipitation in various whey they are autoclaved.

The cheese whey starch suspension was used during spray drying the starch content increased the physical properties of the bacteria. Biological oxygen demand (BOD) was assessed and so was the cell count before and after the 
growth of the strain and even during storage they were assed in every 2 months.

The variance and least standard deviation were analyzed for growth of stain in MRS and formulated broth with enhanced composition for nutrient needs of bacteria. $L b$. gasseri 37 showed significant difference as they required more nutrients for growth in cheese whey. But the BOD was significantly reduced to half in Lb. rhamnosus 64 this resulted in reduced cheese whey load. The growth of the strain remained the same in the whey showing some stability. Lb. paracasei JP1 showed satisfactory growth in cheese whey as well as ricotta whey. It's seen that cheese whey was the most common whey for the strains for better growth.

The air flux and inlet temperature are independent variables whereas outlet temperature and moisture content in spray drying technique were dependent variable. Increasing outlet temperature and moisture declines the survival rate of probiotics. The moisture content needs to be within $5 \%$ and outlet temperature within $850 \mathrm{oC}$.

The thermoprotectant factor was also tested for cheese whey starch suspension and skim milk starch suspension. There was no significant difference in cell count during storage of $L b$. paracasei JP1, and Lb. rhamnosus 64.

For future work as Lb. gasseri 37 couldn't grow well with cheese whey on introducing fed batch process it might be able to take up the nutrients administered from time to time.

\section{Fermented Fruits and Vegetables of Asia: A Potential Source of Probiotics}

It's not a hidden fact, that the world's population is increasing at an alarming rate and people of all domains are trying their best to provide the required nutrition that humans need in all forms possible. One such form that's addressed worldwide is the introduction of probiotics in the fermented fruits and vegetables. The main idea being to increase the shelf life, reduce harmful toxins and also act as a source of probiotics by harboring the growth of Lactobacillus.

It's noted that Lactobacillus is a gram positive bacteria, rod shaped, prefers acidic medium that's achieved by the formation of lactic acid, and the requirement of anaerobic condition. Lactobacillus can undergo homo or hetero fermentation that is production of lactic acid alone or lactic acid along with acetic acid and carbon dioxide respectively. To introduce fermentation there is a need to add starter culture such as Lactobacillus plantarum as it provides reliability and consistency in the product formed.

Fermentation is a common process in most households as it produces alcohol or organic acids from carbohydrates. Amongst Asian countries there has been an age old tradition of consuming fermented fruits and vegetables which also turns out to be a source of probiotics. There are various fermented vegetables and fruits consumed in India, such as leaves of royosag, cauliflower, and cabbage on fermentation produce Gundrunk which is consumed in Himalayas. Many other products include Sunki (Radish taproot is pit fermented), Khalpi (Cucumber fermentation), Inziangsang (Mustard leaves are fermented), Soidon (Tip or apical meristem of mature bamboo shoot is fermented), and Goyang (Leaves of maganesaag are fermented). There are even more fermented fruits and vegetables in other Asian countries. Some of them also exhibit maximum levels of vitamin $\mathrm{C}$ content as in the case of Kimchi.

These probiotics can overtake the antibiotics by stimulating the body's natural defense mechanism and suppressing the pathogens and allowing gut microflora to bloom. One of the major criteria for probiotics is its survival in the gastrointestinal tract, antimicrobial activity against pathogens, adhesion on the epithelial cell and induce immunity.

The vegetables and fruits need to be pretreated for fermentation. As plant cells have pectin in its cell wall, there is a need to break it down and that's done by smoothing the cell wall through pectinolytic enzymes. This allows better growth of lactic flora. There are additional substances such as salt, antiseptic substances such as garlic that prevents spoilage, and a modified $\mathrm{pH}$ and buffer system for $\mathrm{LAB}$ to consume all the sugar present.

The LAB strains are isolated through techniques such as RAPD-PCR, RFLP, and gel electrophoresis and so on. RAPD-PCR has a set of short primers that attach to random DNA length of bacteria and are amplified and then the genetic makeup is read. In the case of RFLP we use restriction enzymes that cut DNA in varying length and then it's read on gel electrophoresis.

There are listed benefits of probiotics on humans, some of them being reduced serum cholesterol, improves gastrointestinal functions and a lot more. Enhanced food quality and safety (ex; lactase present in fermented food changes lactose to galactose). Galactose is seen to have an effect on brain development of infants. The fermented fruits and vegetables have pigments such as anthocyanin which act as antioxidants and help scavenge cancer.

With the existing strains of LAB we can possibly genetically engineer the desired traits in a single species and ferment food with all beneficial effects into one.

\section{The use of probiotics in aquaculture}

Aquaculture is gaining importance with growing population, so when aquatic animals are diseased there is a lot of loss experienced. It's necessary to provide an environment which helps prevent diseases and also increase immune response to pathogens which enter the host.

All of the necessary changes are brought about by introduction of probiotics via feed or water routine. They improve disease resistance, health status, growth performance, feed utilization, stress response. Probiotic brings microbial balance in the ambient environment of the host. The probiotic is usually isolated from the gut of 
aquatic animals. The probiotic needs to fulfil certain criteria to be administered into the host.

The probiotic can be a bacteria and non-bacteria candidate. The non-bacteria candidate involves yeast, algae, and bacteriophage. All of them impart significant contribution to the host's health. Gram positive bacteria are widely used due to their ability to produce spores and Bacillus subtilis. Lysogenic phages have a property of making non virulent bacteria into virulent ones. Saccharomyces cerevisiae provided resistance towards vibriosis of juvenile penaeids.

Administration of probiotic has various categories to be kept in mind with each species or even strain for that matter. 1) Probiotic could be administered as water additive or feed additive. There is no such priority for either. Whichever techniques feel easier with regard to the stain or species of choice. 2) There are questions on whether a multi species or multi-strain probiotics are better than single strain. There have been studies proving that multispecies or multi-strain probiotics have better benefits. Ex: "mixture of B. subtilis and Lactobacillus acidophilus enhanced hematocrit values and serum bactericidal activity in Nile tilapia compared to those exposed to single cultures." There are synbiotics which contain probiotics and prebiotics. These enhanced the survival of animals.

3) Live feed encapsulation helps deliver it to the gut and be viable too. Live probiotics benefits the host but some dead and inactivated probiotics also do the same. There is no evidence as such for which one is better. But there are few examples which showed immune responses being generated. 4) The dosage composition is different based on the physiological status, rearing conditions, and the purpose for which the probiotic is being administered. The more or less ideal concentration found to be was $107 \mathrm{CFU} / \mathrm{ml}$ because of stronger stimulatory effects because it enhanced the innate immunity. Overdose leads to immunesuppression. 5) The time duration for probiotics has shown good results in short term than in long term. The probiotics were not able to stimulate the benefits after 1-3 weeks; also the probiotic didn't reach the GIT. Daily dosage seems to have prolonged effect than when it's administered every other day.

Colonization capacity of probiotics takes two modes of actions that are competitive exclusion and immunomodulation. The probiotic on reaching the gut fights with the pathogen for the nutrition and oxygen and finally adheres to the epithelial cells. While competing with pathogens the probiotics produce bacterial inhibitors and allow the animals to be more resistant to fungi, viruses, and so on. This is nothing but enhancement of the immune system by increased leukocytes, monocytes, complement activity and so much more" Bacillus pumilus, and $B$. licheniformis enhanced immune system of Nile tilapia and rohu respectively."

There are positive health changes in aquatic animals as seen earlier. There is an improvement in water quality as it removed harmful pathogens and enhanced decomposition of organic matter. Improved growth and survival, also helps with digestion due to enhancement of digestive enzymes.

Some concepts still lie unanswered for probiotics that are to be administered to aquatic animals. There is still need to know which probiotic can be given to which species. There is a protein shortage in the feed of fishes and we need to find alternatives for the shortage of protein. All these questions need to be answered later on.

\section{Strategies for improving production performance of probiotic Pediococcus acidilactici viable cell by overcoming lactic acid inhibition}

As probiotics are becoming an essential part of food industries it's important to have a high density of viable cells for effective effect. Pediococcus acidilactici is a probiotic found in oral, alimentary and gastrointestinal tract.

The 3 types of fermentation are batch, fed batch and continuous fermentation. The best amongst them is fed batch fermentation as there is supply of nutrients as they cells don't suffer due to depletion of nutrients. Hence the conversion of batch fermentation to fed batch fermentation was conducted on P. acidilactici. Anion resin exchange was performed on fed batch fermentation to improve growth.

P. acidilactici was taken from Merck Millipore, Germany. They were cultured on MRS medium and were incubated at $37 \mathrm{o}$ C. For fed batch fermentation process $2 \mathrm{~L}$ stirred tank bioreactor were used. Different feeding rates, $\mathrm{pH}$, temperature, anaerobic/ aerobic conditions, glucose concentration were noted to know the effect on the lactic acid accumulated from P. acidilactici.

Initially the culture was allowed to ferment until the glucose in it was completely exhausted i.e. batch fermentation, after which glucose was added until the final volume of glucose added was 1L making it fed batch fermentation. The lactic acid produced is absorbed by anion exchange resin and can be reused by washing it with $4 \%$ $\mathrm{NaOH}$. The glucose and lactic acid were determined using reverse phase high performance liquid chromatography.

Specific glucose concentration that is under $10 \mathrm{~g} / \mathrm{L}$ increased the viable cell count, but more than $10 \mathrm{~g} / \mathrm{L}$ decreased the cell count. The lactic acid was added in the exponential phase as prior to that the cells died due to extreme acidic condition. Lactic acid concentration only inhibited the growth of cells. The lactic acid produced with or without $\mathrm{pH}$ control was the same for P. acidilactici. Viable cell concentration, viable cell yield and viable cell productivity obtained were slightly higher in facultative condition than anaerobic condition. The lactic acid yield was higher in facultative condition. Though the viability, productivity, and yield of the cell were the most in $300 \mathrm{rpm}$ the lactic acid produced was almost the same in 200 and $300 \mathrm{rpm}$. But at $400 \mathrm{rpm}$ the lactic acid productivity was less. 
In fed batch fermentation highest cell viability was obtained in $0.015 \mathrm{~L} / \mathrm{h}$. Highest lactic acid was produced at $0.08 \mathrm{~L} / \mathrm{h}$ and $0.03 \mathrm{~L} / \mathrm{h}$. The viability of the cell, the yield, the lactic acid production was different for batch fermentation and fed batch fermentation. When it came of anion exchange resin the highest adsorbed component by IRA 67 resin was lactic acid, followed by acetic acid, sodium acetate and glucose.

The growth of P. acidilactici was found to be more in fed batch fermentation with resin. Apart from that the yield, productivity, accumulation, and production were different for both with or without resin fed batch fermentation.

Bacterial growth was seemed to be reduced due to the presence of lactic acid accumulation. P. acidilactici undergoes homofermentation causes even more lactic acid content. Due to increased acidification the medium needs to be neutralized or the lactic acid needs to be removed, due to lactic acid the energy needed by the cell for the growth is reduced. Even on neutralization the addition of $\mathrm{NaOH}$ caused some lactic acid to dissociate into lactate ion and others that are undissociated diffuse through cell membrane and then disrupting inside the cytoplasm causing change in $\mathrm{pH}$ gradient.

The facultative condition is coined in terms of how aerobic condition i.e. presence of oxygen can be toxic to the cell. So before inoculation the oxygen level is made to $100 \%$ and then stopped.

By knowing all these factors which inhibit growth of $P$. acidilactici it can be used to study its health benefits on humans or animals and be produced in the most viable form for storage and usage in a longer period of time. Similar strategy can be employed for even more economical, health wise beneficial to mankind to cure diseases.

\section{Identification and antibiotic susceptibility of bacterial isolates from probiotic products}

Probiotics are highly used in dairy products and few food supplements in various countries. Probiotics are beneficial to health, earlier studies showed that Lactic acid bacteria has many health promoting properties so it is considered as one of the main probiotics. Nowadays it was observed that probiotic products are highly available in many European markets but it was found that there are many mislabelled probiotic products available in many markets. As there is an increasing demand for probiotic products in day-to-day life, it is necessary to identify correct probiotic strain and labelled them correctly on product.

In the present study scientists verified correct labels of European dairy and food products and checked antibiotic susceptibility of product isolates. Temmerman et al. (2002) studied a total 55 European probiotic products including 30 dried food supplements and 25 dairy products which was collected from 8 European countries' markets. Bacterial isolation was done using various selective media followed by bacterial strain identification using SDS PAGE method.
Colony count of dairy products identified as $10^{5}$ to $10^{9}$ $\mathrm{CFU} / \mathrm{m}$ and for food supplement it was below 1 to $10^{6}$ $\mathrm{CFU} / \mathrm{g}$. Protein analysis done by the whole cell protein method and compared with the available protein pattern of LAB. Enterococcus faecium and Lactobacillus rhamnosus were observed most frequently available in food supplements. Bifidobacterium successfully isolated and identified only from 3 products among 13 food supplements and found in only 2 dairy products. Lactobacillus acidophilus is found in only 2 products among 22 products. In this study after verification of products scientists confirmed that there are many mislabelled products available in the market.

Among 268 isolates from probiotic products 187 isolates were checked for its resistance against six antibiotics i.e., kanamycin (30 Ag), vancomycin (30 Ag), erythromycin (10 $\mathrm{Ag})$, tetracycline (30 Ag), chloramphenicol (30 Ag) and penicillin $\mathrm{G}$ (10 A) using agar disc diffusion method. Most probiotics from genera Lactobacillus and Enterococcus showed high resistance against kanamycin (79\%). It was observed that most bacteria showed resistance against vancomycin (65\%). E. faecium isolates showed $38 \%$ resistant against vancomycin. It was found that the lactobacilli strains are resistant to tetracycline $(29.5 \%)$, chloramphenicol $(8.5 \%)$, and erythromycin (12\%). Among total studied isolates more than $68 \%$ isolates showed resistance to two or more antibiotics. Bifidobacterium longum, Bifidobacterium lactis, Lactobacillus delbrueckii ssp. Bulgaricus found only resistance against kanamycin.

From this study it was clearly observed that most of the food supplements and dairy products are mislabeled which need to labelled correctly on product. Bifidobacterium spp. isolation conditions need to understand further. Most of the probiotics are shown as resistance antibiotics, however still we have to give more attention towards some strains of probiotics, its antibiotics susceptibility activity against other antibiotics.

\section{Culture-Independent Analysis of Probiotic Products by} Denaturing Gradient Gel Electrophoresis.

As probiotic bacteria are considered as beneficial to host when consumed in particular concentration present in probiotic products. As earlier reported, there are many mislabelled probiotic products available at various markets in terms of isolated strains and its concentration present in the product. Probiotics are mainly found in fermented products and because of their beneficial role in health issues they are commercially available as tablets, food supplements and in powder form. Thus, it is necessary to isolate correct beneficial strain of probiotics and label the products correctly with its strain and concentration. In many studies' probiotic strains were isolated and analysed using culture dependent methods with the help of certain selective media. Though, selective media has certain limitations in terms of recovery and not all probiotic strains are able to isolate using culture-dependent methods. So, in this study Temmerman et al. 2003 used cultivation- 
independent methods for identification and detection of bacteria in probiotic products and compared it with using cultivation-dependent methods further. Analysis of probiotic product strain was done using denaturing gradient gel electrophoresis afterwards.

In this study 10 dairy samples were examined i.e., four dairy products, one fruit drink, and five freeze-dried products. In culture dependent methods bacteria were isolated using selective media from product samples followed by identification of isolates using SDS-PAGE technique. Cell suspension of particular strain was made to check DNA reliability. It was observed that not all probiotic species from the 6 products sample (Actimel, Vitamel, Aciforce, Bacilac, Bififlor, and Proflora) were able to grow in culture dependent methods.

In culture independent method, DNA extraction is done directly from available dairy products with the help of lysozyme and centrifugation. Amplification of the V3 region of $16 \mathrm{~S}$ rDNA of each sample was done with the help of PCR technique. For the direct analysis of strains DGGE (denaturing gradient gel electrophoresis) performed with reference strains of bacteria for identification. 35 to $70 \%$ denaturant DGGE gel was used for each 10 product samples on which amplicons produce from previous PCR technique loaded and further with the help of reference strains final probiotic strain present in dairy samples identified. The complete identification of strain using DGGE completed within 30 hrs.

Further scientists compared the results of culture dependent and culture independent methods in which it was observed that, for products (Actimel, Vitamel, Aciforce, Bacilac, and Bififlor) DGGE analysis was able to detect more species than were recovered by isolation. For the product, Bacilac and Vitamel, some other species which was not mentioned on the product was detected and identified through DGGE technique. It was found that the detection limit of PCRDGGE is $10^{4} \mathrm{CFU} / \mathrm{ml}$ through this study. Thus, from this study scientists clearly found that culture dependent methods not that useful in identifying and isolating all the probiotic strains from the probiotic product.

As increasing microbial strain complexity, DGGE method found to be more beneficial to identify exact strain of microorganisms. So, in this study scientists clearly demonstrate that DGGE is a fast, reliable culture independent technique for identification of strains than normal culture dependent technique.

Identification and characterization of starter lactic acid bacteria and probiotics from Columbian dairy products.

The use of dairy products in day-to-day life is increasing in various countries. Earlier reports confirmed that some probiotic bacteria provide various health benefits to the host. It was found that probiotic bacteria and starter bacteria are highly involved in production of dairy products. Mostly probiotics selected from genera Lactobacillus and Bifidobacterium because they have a high beneficial effect in the dairy industry. In previous studies scientists did not find any detailed report on probiotic strain performance and concentration in probiotic products from different producers in Columbia. Thus, by considering increasing probiotic products demand in Columbian markets Velez et, al (2006) examined numbered of viable starter lactic acid bacteria and probiotics from bio-yoghurt available at Colombian market and checked its antagonistic activity against harmful pathogens as well as bile acid resistance and adherence capacity to human intestine

A total of seven yoghurt samples were used in this study from Columbian supermarket. Bacterial isolation done by serial dilution in PBS followed by streaking using different media. de Man Rogosa Sharpe (MRS) used for LBS isolation, M17 agar for Lactococcus isolation, ST agar for $S$. thermophilus isolation and RB agar used for Bifidobacterium isolation. After incubation in aerobic and anaerobic conditions. Bacterial strain identified using amplifying 16S rRNA with the help of PCR and performing BLAST. Further antimicrobial activity of isolated bacteria was assayed using LB agar plate and its antagonistic activity determined. In this study the commercial strain $L$. rhamnosus GG (ATCC 53103) used throughout as a positive control.

Streptococcus thermophilus and L. delbrueckii ssp. bulgaricus were found in high amounts from all the yogurt samples. Viable Bifidobacterium cells were isolated from only one sample, but surprisingly it was not mentioned on that product. Strain F-3 (L. paracasei) found to have strong antimicrobial capacity on Salmonella typhimurium strains SL1344 and ATCC 14028. Whereas, Inhibitory activity of strain C-1 (Lactobacillus casei) was found to be strong against strain SL1344, but not against strain ATCC 14028.

Survival of isolated strains from samples in the gastric juice environment were checked with the help of MRS medium. Only strain A-1 (Lactobacillus paracasei) and B-1 (Leuconostoc mesenteroides) were found to have survived over 90 mins in gastric juice as well as they showed adherence to the Caco- 2 cells while performing adherence assay. Strain F-2 (L. delbrueckii ssp. Lactis) and F-3 (L. paracasei) also able to adhere to Caco- 2 cells.

Thus, from this study scientists successfully identified some beneficial probiotic strains (A-1, B-1, F-2 and F-3) present in yogurt samples. However not all strains found to be beneficial in dairy products. From this study it was observed that the full correct scientific name of the isolated bacteria and their viable counts were not included on the product label in the Columbia market. It was interesting to study further other beneficial probiotics in other dairy products.

\section{Characterization of Some Bacteria Isolated from Oreochromis niloticus and their Potential Use as Probiotics}

Aquaculture is considered as one of the most important factors in the environment. In previous studies scientists 
identified that some bacterial infections are a major cause of mortality of fishes in aquaculture. Thus, in this study Aly et al. (2008) examined the use of probiotic bacteria to control disease causing pathogens in fishes and tried to reduce its mortality rate. Scientists isolated probiotic bacteria from Oreochromis niloticus and checked its ability in vivo and in vitro to control the pathogenic effect of $A$. hydrophila on $O$. niloticus.

Forty $O$. niloticus were randomly collected from earthen ponds of the World Fish Centre, Abbassa, Egypt. After bacteriological examination of fish samples their swab samples were taken and cultured on tryptic soya broth (TSB). After incubation at $30^{\circ} \mathrm{C}$ for 1 to 2 days, subculturing was done on tryptic soya agar (TSA). Further by performing biochemical tests the pathogenic strain of $A$. hydrophila was identified. Pathogenicity of isolated $A$. hydrophila were checked on randomly selected 120 healthy $O$. niloticus by injecting $A$. hydrophila bacterial suspension to fishes through IM (intramuscular), inoculated IP (intra peritoneal) way with $0.2,0.5 \mathrm{ml}$ concentration respectively. Mortality rates were examined further for 14 days which was $100 \%$ found.

Further 15 isolates were selected on the basis of morphology and examined its in vitro probiotic activity against pathogenic strain of $A$. hydrophila and assessed probiotic activity in vitro using agar diffusion method. Out of 15 isolates only 3 isolates were identified as a probiotic based on their phenotypic and the biochemical characters (B. pumilus, B. firmus and C. freundii). The B. pumilus, $B$. firmus and $C$. freundii showed inhibitory effects against $A$. hydrophila in vitro.

The viability of probiotic bacteria in the diet of fishes were assessed, it was found that. B. pumilus survived at either 4 ${ }^{\circ} \mathrm{C}$ or $25{ }^{\circ} \mathrm{C}$ for five weeks but B. firmus and $C$. freundii were no longer found viable in the feed stored at $25^{\circ} \mathrm{C}$ after 2 and 1 weeks of storage, respectively. Thus, the factors affecting the growth condition of B. firmus and $C$. freundii was not that much clearly understood in this study.

In a feeding experiment it was found that these three probiotic bacteria succeeded in reducing pathogenic effect on $O$. niloticus. But the highest survival of fish was observed with a diet supplemented with $B$. pumilus, followed by a mixture of probiotics. Thus, from this study it is clear that $B$. pumilus acts as a promising probiotic bacterium in controlling the pathogenic effect of $A$. hydrophila in aquaculture.

\section{Probiotics in aquaculture: Challenges and outlook}

Aquaculture is one of the most modern factors in the environment. Nowadays increasing sea food demand has led to the development of the aquaculture industry all over the world. Day-to-day deterioration and some diseases cause serious loss of environment. In recent years prevention of diseases with the help of chemical additives and medicines led to some environmental problems. Thus, the probiotics are considered as alternatives to the chemical additives as it is beneficial in disease control and environmental conditions. The probiotics are able to balance in intestinal microbes. Wang et al. 2008 reviewed the role and use of probiotics in the aquaculture industry.

In the aquaculture industry there are many probiotics used commercially to feed aquatic animals like fishes, shrimp and molluscan farming as they are safe and effective in supporting the health of aquatic animals. Probiotics are also used to incorporate in pond water as it has an important role in pond culture, water quality etc. Probiotics contribute to the health and well-being of the hydrobiont in aquaculture. The digestive tract of hydrobiost constantly surrounded with water. Their digestive tract is richer in nutrients which is beneficial for the growth of microorganism, thus digestive microflora of hydrobiont plays the main role in resistance of disease. Gastrointestinal tract takes part in decomposition of nutrients and provides vitamins and enzymes to microorganisms.

Some probiotic bacteria also have antiviral effects although the exact mechanism of its action is not known. Some laboratory tests indicated that inactivation of virus occurs due to extracellular agents of marine bacteria as well as extracts of marine algal components. In the preparation of probiotics, it is necessary to maintain its pathogen resistance properties throughout the process. Due to physical and biological properties like spore formation, Bacillus spp., includes B. subtilis, B. cereus, B. coagulans, B. clausii, B. megaterium and B. licheniformis, are used as probiotics. It is important to maintain stability of probiotics throughout its preparation.

The research on use of probiotics in aquatic animals is increasing, as demand of the environmental aquaculture industry is increasing. Most probiotics used in aquaculture belong to the genus Bacillus or yeast, although their detailed species level identification is not yet known clearly. In aquaculture mostly LAB is considered as a safe probiotic as it has no adverse effect on aquatic animals and because of its beneficial properties. New probiotic strains are now day by day identified and used for the aquaculture industry. Furthermore, with the help of modern molecular techniques should be used to identify correct species of beneficial probiotics and their detailed role in aquaculture.

\section{Isolation of Saccharomyces cerevisiae strains from different food matrices and their preliminary selection for a potential use as probiotics.}

In recent years there is an increasing demand of new beneficial food components in food markets. Probiotic product demand is increasing in food markets because of its beneficial effect on consumers' health. As earlier reported, probiotic bacteria mainly belong to genera Lactobacillus and Bifidobacterium. The use of yeast in dietary supplements is still limited. It was observed that many yeasts can control pathogenic microorganisms, they can survive in low $\mathrm{pH}$, can tolerate bile salt concentration in GIT, thus it can be considered as one of the beneficial 
probiotics. Though use of yeast in human food is still limited.

In this study Pennacchia et. In 2008 studied some probiotic yeast strains from eight food sources (Traditional Salame, Wine, Traditional Soppressata (sample A and B), Natural starter culture for the production of Mozzarella di Bufala Campana, Caciotta cheese, Sour-dough). Samples were collected from Campania region, Calabria region and Toscana region. Ten grams of food matrices collected from all samples for study. Rapid bacterial isolation carried out directly from samples. The isolation of 22 yeast strains resistant to a simulated passage through the human GI tract done using malt extract agar medium followed by checked its capacity to tolerate bile and low $\mathrm{pH}$. Among 22 yeast strains on the basis of its survival results in GI tract, 10 isolates selected for API-ZYM test to check its lipolytic and proteolytic enzyme activity. All the Saccharomyces strains were observed to have unique in exhibiting b-glucosidase activity which is responsible for the hydrolysis.

Molecular identification of selected 10 yeast strain examined with DNA extraction followed by amplification of 5-8S-ITS region and RFLP analysis. The results of the sequencing of the D1 D2 domain of the 26S rDNA of the 10 selected yeast strains indicated that yeast strain belonged to the $S$. cerevisiae species, $C$. parapsilosis/metapsilosis, $C$. pararugosa and Pichia galeiformis/ membrane ifaciens/ manshurica, species respectively.

In this study human intestinal fluid prepared by $0.3 \%$ of bile salts and $0.1 \%$ of pancreatin. 10 strains showed a good survival percentage in GIT and stomach. Strain H3 Saccharomyces cerevisiae $71.5 \%$ and strain Candida parapsilosis / metapsilosis $94 \%$ of demonstrating a satisfying tolerance to bile salts and pancreatin exposure.

Thus, from this study on the basis of identification and certain tests performed three yeast strains with the best probiotic performance observed which belonged to the species C. parapsilosis/metapsilosis (C2 and C3) and Pichia galeiformis/membranifaciens /manshurica (G3). Also, five strains of $S$. cerevisiae observed with best probiotic activity which can be use further in food industry as a probiotic.

\section{Microbiological and genetic identification of some probiotics proposed for medical use in 2011}

Many reports concluded that probiotics plays the main role in many diseases control and improvement of health conditions when consumed in sufficient amounts. Probiotic products available in the form of conventional foods, food supplements and dietary supplements as a capsule. Usually, probiotic properties observed in multiple strains of LAB belong to genera Lactobacillus, Lactococcus, Pediococcus, Enterococcus and Streptococcus. Also, Bifidobacterium, Propionibacterium, Bacillus, Escherichia coli and the yeast Saccharomyces boulardii have been reported as probiotic. As there are increasing probiotic products in Italian and European market it is necessary to determine the correct label on products. Earlier some studies identified mislabelled in terms of viable probiotic microorganism count and correct identification of bacterial strains present in products.

In this study Toscano et al evaluated if dietary supplements for medical use available in Italian and European market in 2011 were correctly labelled or not and the number of viable bacteria counts identified. 24 commercial probioticbased dietary supplements available on the Italian market in 2011 were included into the study. Bacterial isolation done using selective media followed by morphological and molecular techniques used to identify strain. Scientists compared isolated strains and labels on products. Fourteen products were found to have correct labels in terms of viable bacterial count and identification of bacterial strain Ten products were found to contain incorrect viable count of bacteria and four products did not detect any bacterial strain.

Contamination detected in two products by Enterococcus faecium. Thus, in this study scientists found some deficiencies in about $40 \%$ of the products and concluded that probiotic products available in Italian and European market need to be examined correctly and should be labeled correctly on products.

\section{Sources, isolation, characterisation and evaluation of probiotics}

Fontana et., al. (2013) reviewed the sources, isolation methodology, characterisation and evaluation of probiotic strains. In the present study scientists summarised the total 1500 work published in the PubMed database from February 2012. The detailed information regarding probiotic strain isolation, sources and its beneficial effect on host Fontana et., al. (2013) summarised in this literature review.

Dairy and dairy related products are the most common sources reported for probiotics especially for Lactobacillus and Bifidobacterium. Sources like yak milk, kefir grains, Masai milk, Cheese, breast milk, human GIT, colonic mucosal biopsy samples, faecal samples, Apis mellifera L. bee gut, meat, olives, and pickled juice were reported for isolation of probiotic strains in this study. Isolation of probiotic bacteria carried out using different selective media and plates are incubated at $37^{\circ} \mathrm{C}$ for $48-72 \mathrm{~h}$. Further identification of microbes is the most important step carried out to select potentially important probiotics from the sample. Taxonomic classification done which involves genotypic and phenotypic methods to identify bacteria.

16S rRNA gene analysis methods reported in many studies for identification of probiotic strains. Amplified 16S rRNA gene used to identify bacterial communities in combination with techniques like PAGE, DGGE (denaturing gradient gel electrophoresis), fluorescence in situ hybridisation, Terminal restriction fragment length polymorphism (TRFLP). Characterisation of probiotic bacterial strain done on the basis of its beneficial effect i.e., bacteria must overcome the GIT barrier, survival in low $\mathrm{pH}(1 \cdot 5-3 \cdot 0)$, 
capacity to tolerate gastric enzymes and bile salt concentration.

Adherence to intestinal epithelial cells is one of the important characteristics of probiotics. Caco- 2 cell line has been reported in many studies to check adhesion capacity of isolated bacteria. Colonic cell line HT-29, Caco-2, Caco-2 plus mucus, HT-29 MTX and Caco-2/HT29MTX reported to use in vitro adhesion assays. Antimicrobial activity of several probiotic strains checked against Listeria monocytogenes and Helicobacter pylori in vitro, and in vivo using several animal models. Several strains of Lactobacillus and Bifidobacterium found to inhibit Escherichia coli, Salmonella typhimurium, Shigella flexneri and $C$. difficile.

The safety of each isolated probiotic strains examined in probiotic products before processing to market. It has been found that probiotic characteristics of bacterial species vary with strain to strain. Further with preclinical evaluation with the help of animal models followed by clinical evaluation of probiotics in various diseases evaluated.

Thus, scientists concluded that various beneficial probiotics are available in many sources with several beneficial effects on hosts. The emerging probiotic strains can be identified and characterised with modern techniques further.

Potentially probiotic acetic acid bacteria isolation and identification from traditional dairies microbiota

It was found that probiotics can maintain normal human microbiota compositions as well as it can reduce the risk of many human diseases. Majority of probiotics are found to include lactic acid bacteria (LAB). Probiotics mostly found in fermented dairy products. Many probiotics are eliminated from the body due to low acidic and high bile concentration. Acetic acid bacteria (AAB) can be considered as probiotic due to their strong fermentation and acidification activity. In this study scientists tried to obtain novel acetic acid bacteria strains with high probiotic capability from traditional dairy products in Iran.

Total 200 samples from traditional dairy products in Iran including cheese, yogurt, curd, shiraz, and tarkhineh were used to isolate Acetobacter strains. Bacterial isolation carried out using MRS agar at $37^{0} \mathrm{C}$ for $24 \mathrm{hrs}$ followed by biochemical tests and morphological screening. Twentythree isolates of AAB found after morphological identification and primary screening. Further 8 Acetobacter strains were confirmed using combined repetitive sequencebased PCR [(GTG)5-PCR fingerprints] and 16S rDNA gene sequencing with the help of nine reference Acetobacter strains. Species level identification and characterisation done using BLAST software. After BLAST analysis eight strains identified belonging to four species i.e., Acetobacter aceti, Acetobacter indonesiensis, Acetobacter cibinongensis and Acetobacter syzy.

A. indonesiensis, A. cibinongensis, A. indonesiensis, strains were isolated from yogurt samples. Acetobacter strains, A. cibinongensis, A. syzygii (38Lac), A. indonesiensis, A. syzygii $(6 \mathrm{H})$ were isolated from curd samples. Strain $A$. aceti $(18 \mathrm{HN})$ were isolated from Tarkhineh dairy samples. All eight isolated Acetobacter strains showed moderate tolerance to acidic conditions ( $44 \%$ to $78 \%$ ) and found to retain their viability more than $3 \mathrm{hrs}$ in low $\mathrm{pH}$ after performing assay.

Acetobacter strains, Acetobacter cibinongensis (34L), A. indonesiensis (10HN) and A. syzygii (38Lac) showed high survival rates under low $\mathrm{pH}$, significant antipathogenic activity in antimicrobial assay. Acetobacter cibinongensis (34L) showed high inhibitory activity against the majority of pathogens. Acetobacter strains were found resistant to erythromycin, vancomycin and sulfamethoxazole antibiotics in antibiotic assay.

As antimicrobial properties of Acetobacter strains show higher antagonistic activity than lactic acid. Thus, from this study scientists identified that Acetobacter strains can be used as beneficial probiotics. Modern method GTG-PCR fingerprinting is found to be very convenient to identification and discrimination between species level strains. In this study after observation of all the results scientist concluded that Acetobacter cibinongensis $34 \mathrm{~L}$ strain, isolated from traditional curd could be serve as an effective probiotic as it displayed high antibiotic susceptibility, antipathogenic activity and high tolerance activity to low $\mathrm{pH}$ and bile salt conditions.

\section{Identification and probiotic properties of lactobacilli isolated from two different fermented beverages.}

In many regions in the world fermented beverages and food products are highly consumed. Certain fermented beverages based on milk and cereals known to have high beneficial properties. There are many studies earlier which examined fermented beverages and food products in Africa, SouthAmerica, or Asia. There is little information known till date on the number and identification of microorganisms in fermented beverages and products in certain regions of Europe. Thus, in this study Angelescu et al. 2019 tried to isolate and identify lactobacilli strain from water kefir and braga which is Romanian fermented beverage and checked its probiotic potential activity.

Kefir and braga are two fermented beverages made of cereals used in this study LAB were isolated from the samples using (MRS) agar media at $37{ }^{\circ} \mathrm{C}$ for $48 \mathrm{~h}$. bacterial isolates were identified using gram staining and catalase tests. Molecular identification performed using DNA extraction and (GTG)5 primer amplification using PCR. 16S rRNA gene sequencing done for species level identification followed by with help of BLAST software.

Total 15 strains of lactobacilli were found in kefir and braga samples out of only 8 strains examined further for antibacterial activity against pathogens like Bacillus cereus CBAB, Bacillus subtilis B17, Listeria monocytogenes ATCC 1911-1, Staphylococcus aureus ATCC 25923, Salmonella enterica ATCC 14028, and E. coli 
ATCC25922. HPLC analysis done to analyze Lactic acid production. The strain of lactobacilli, Lactobacillus delbrueckii, L. fermentum (four isolates) and L. plantarum (two isolates) were isolated from Braga and Lactobacillus satsumensis, Lactobacillus ghanensis, L. plantarum, and Lactobacillus nagelli, were identified from Kefir water sample.

Probiotic potential of isolated examine by performing in vitro test of acid, enzymes, and bile tolerance and survival of test in gastrointestinal tract. It was observed that $L$. plantarum BR9 and L. plantarum CR1 shows high survival activity in GIT.

Thus, it was observed that LAB composition in water kefir samples is most diverse. MRSg only isolated L. plantarum and L. nagelli, while the other lactobacilli were only isolated from MRSf. L. plantarum BR9 was found to have high inhibitory effect on most of the pathogens as well as it shows high probiotic potential. In this study scientists first time reported the presence of $L$. ghanensis in water kefir in Europe. Based on this study L. plantarum BR9, isolated from braga, and L. plantarum CR1, isolated from water kefir showed high probiotic potential activity which can be used further safely in many beverages.

Isolation, characterization and identification of antigenotoxic and anticancerous indigenous probiotics and their prophylactic potential in experimental colon carcinogenesis.

Cancer is the disease caused due to uncontrolled growth of cells in different parts of the body. The cancer of the colon and rectum is called Colorectal Cancer (CRC). Nowadays $\mathrm{CRC}$ is increasing rapidly in various countries which is affected by certain external as well as internal factors like poor diet, alcohol, tobacco etc. Probiotics are live microorganisms which can act as a preventing agent and can reduce the occurrence of disease. Earlier studies confirmed that probiotics have certain anticancerous activity and can modify gut microbiota, physicochemical conditions of colon and can enhance the gut barrier functions. Therefore, in this paper Chandel et al. 2019 focused on the role of LAB as a probiotic specifically targeted against $\mathrm{CRC}$ and checked its anticancerous and antigenotoxic activity.

Scientists isolated $46 \mathrm{LAB}$ isolates from different sources (26 from infant faeces and 9 from fruit peels) on MRS agar and checked its anticancerous and antigenotoxic activity in vitro.

Scientist further selected only five isolates of LAB (\#14, $20,22,17 \mathrm{~A}$ and 1A) based on its antigenotoxic and anticancerous potential and checked its probiotic activity like acid and bile tolerance and cell surface hydrophobicity etc. Further based on its probiotic activity LAB (14, 22 and 17A) were selected and identified with 16rRNA sequencing techniques. Further with the help of In Vivo study scientists assess anticancerous potential of Lactobacillus rhamnosus, Lactobacillus plantarum, Pediococcus pentosaceus in early experimental colon carcinogenesis. These probiotics were successfully identified in decreasing rate of CRC by increasing body mass and growth, by checking acidic faecal pH when supplemented with L. rhamnosus. By decreasing Aberrant crypt foci (ACF) which is the earlier hallmark of CRC. It was found that these three isolated probiotics can deduce activity of faecal enzymes i.e., $\beta$-glucuronidase, nitro reductase, $\beta$-glucosidase which help in conversion of procarcinogens into carcinogens.

Therefore, from this study we can conclude that isolated LAB probiotics actively helps in reduction of CRC. It is interesting to know further this indigenous probiotic activity against other types of cancers as well and their modulation of various carcinogenic molecular markers

\section{The Production and Delivery of Probiotics: A Review of a Practical Approach}

One of the important aspects includes knowing how we can produce high quality probiotics and how to keep them viable and stable to impart its beneficial qualities to the added products and also while it's added as a starter culture.

Manufacturing of probiotics and starter culture has several steps. The frozen seed are first made to grow to the desired count through sequential seed fermentation or are directly inoculated into main fermentation vessel which contains nitrogen, carbohydrate, water, and micronutrients necessary. Then the cell concentrate are centrifuged, to this they add cryoprotectants and lypoprotectants. Cryopreserved cells are canned and sent to consumer and then the lyophilized cells are sent into nitrogen bath, the frozen cells are put in freeze drying chamber where the temperature increases on vacuum. These pellets are later powdered for use. The product produced is of high quality and free of contaminants.

Moving from lab scale to commercial scale can be a task as the conditions are very different so from lab scale production there is only slight increase in concentration of cell and that is referred as pilot scale. Then from pilot scale it goes on to commercial scale production. If the same robustness isn't found in commercial scale, it's sent back to lab scale for required changes. There is iterative process which involves changing pressure, heat plate temperature, and frozen bed pellet thickness is adjusted for cell count, and shelf life of interest is achieved.

Lactic acid bacteria (LAB) and Bifidobacteria cannot produce proteins of their need hence it needs to be administered externally. To get a high performance end product the microorganisms are given the necessary medium and nutrition. To provide the desired nutritional medium, there is a need to know genomics, gene expression and protein expression for both the bacteria. This could also involve change in raw materials of growth media depending on the strain. Before and after inoculation of bacteria are tested for cross checking the nutritional limitations if there are any. 
Manufacturing process can have lasting impact on the strain being produced. The reasons for this could be manual, automated, or malfunctioning from nutritional aspect too. The nutritional aspect comes in due to scale up from one level to another. To avoid this there is a need to evaluate the samples throughout the process.

End product probiotic needs to be tested for physical, contamination, absence of pathogen, functionality; Identification of probiotic through PCR and 16S sequencing has been the common techniques that are visited. One of the important pointers is to keep the environment in and around the probiotic low as that would lead to hampering of shelf life of probiotic. So various options were tried and tested and having a desiccant proved to be the best choice to have low water activity in and around the probiotic.

Incorporation of probiotic is easier in dietary supplements as compared to incorporation in food. Due to presence of acid and anthocyanins there is change in $\mathrm{pH}$ and water activity around probiotics. Fermented milk seem to be the most traditional probiotic food the probiotic is administered in the form of frozen pellet to reduce mixing time and provide homogenization. Ice cream in frozen format gives a better suited environment for cell viability. But there is production of oxygen which could cause issues. Instead they use aerobic bacteria and are added during the fermentation rather than manufacturing process.

Amidst this is the potential for usage of probiotic in the medical devices for bringing about the benefit the probiotic is intended to deliver.

11) Production and stability of a multi-strain Bacillus based probiotic product for commercial use in poultry

Poultry sector works at low cost margin but high volume production so it's important to maintain to keep the animals health at better conditions. The intake of probiotic incorporated in feed helped improve feed efficiency, weight gain and gut morphology.

The steps in production of probiotic seem to have detrimental effects on the bacteria due to mechanical sheer, high temperature and pressure the probiotic seems to undergo lose. It's also proven that sporulation of Bacillus species can withstand harsh conditions due to this most probiotics are intended to be given in form of spores for better viability, efficiency, and stability in poultry.

There are various techniques that are carried out include the basics ones for isolation and production of any microorganisms, but the materials and conditions applied to it would vary a lot depending on the species. There were 6 strains of Bacillus species and the minimum concentration for each strain was intended to be $1 \times 106 \mathrm{CFU} / \mathrm{g}$.

Inoculum for all the 6 strains were prepared used tryptone soy broth and were tested for culture purity later by using tryptone soy agar (TSA) and spectrometer for the OD660nm reading. The bacillus species were batch fermented using bioreactor and the temperature, pressure,
$\mathrm{pH}$, oxygen level were maintained based on the strain that's being fermented. They were later stored for $24 \mathrm{~h}$ after which they were taken out in $3 \mathrm{~h}$ interval for sample analysis. The cell concentration, Spore efficiency were calculated through culturing on TSA.

The cells are harvested post fermentation and the viable concentration is noted for the same. The centrifuges strains are dried by mixing the liquid pellet with inert clay and then the dried strains are pin milled to powder form. The mass of powdered probiotic is reached by adding calcium carbonate dextrose carrier to it. They sugar gives protection against oxidative damage to the probiotic and the calcium carbonate helps in adhering to the intestinal cells. After this the probiotic product formed as a multi strain product is sealed and stored in ware house for 12 months after 12 months the spore concentration remained in the minimum concentration.

After this it's very important to check the viability and stability of the multi strain bacillus based probiotic in the gastrointestinal tract. The powdered boiler feed was mixed with sterilized simulated gastric fluid (SGF) then they are mixed well followed by addition of water, this is the depiction of boiler fed in the stomach of the animal to this the powdered probiotic is added and the minimum spore concentration was achieved.

The mean retention time for the probiotic varies on some many factors such as sex, age and environmental condition.

\section{Isolation of Probiotics from Yeast and their Usage as Food Complements}

This study aimed to isolate strains of Saccharomyces cerevisiae that were acid-resistant as well as bile resistant. These strains were obtained from different food samples and were preliminarily selected concerning their significant probiotic characteristic. The live micro-organisms that can be exercised as food or pharmaceutical complements and upon ingestion and interest human or animal health by emphatically concerning the main advantageous functions of normal intestinal micro flora are called probiotics. Currently, the yeast probiotics are obtained from the genus Saccharomyces. The usage of yeasts as effective dietary complements is still unsatisfactory. Only one yeast strain is commercialized to be used in the fields of health medicine.

Therefore, the purpose of this study was to choose various food substances and isolate $S$. cerevisiae strains from them which exhibit potential probiotic properties like- capability to sustain in the human gastrointestinal tract, acid tolerance, and bile tolerance.

The isolation and selection were done concerning the previous procedures. To conclude, this study describes an effective approach to pick and recognize Saccharomyces cerevisiae strains with beneficial probiotic properties.

Isolation of Probiotics along with their Characterization and Sources 
The prokaryotic microorganisms that possess the potential to present health advantages to the host upon ingestion are called probiotics. Lactic acid bacteria and bifidobacteria are the two most prevalent strains of bacteria utilized for the isolation of probiotics. The characterization of probiotics is performed before its isolation and separation. The significant characteristics that necessitate being possessed by these probiotics are- non-pathogenic, non-toxic, hazardous side effects free, survivability in the gastrointestinal tract, possession of host-beneficiary effects, and compatibility with product matrix and storehouse circumstances. The disparate origins of probiotics comprise dairy, non-dairy, and poultry products, the gastrointestinal tract of humans, rats, pigs, bees, fishes, and poultry animals, fit adults, and infants fecal samples and breast milk from females, fruits, vegetables, and juices. The isolation of probiotics is performed by sustaining their samples and placing them under anaerobic conditions spontaneously. This is accompanied by the processing of these probiotics which includes homogenization, dilution, and culturing in suitable media until they are ready for incubation which would hasten their growth. The colonies of probiotics are then segregated from the sample. The separation of probiotics is performed before its identification and characterization and the techniques concerned in these processes are-gene sequencing, specific primer selection, gel electrophoresis, genetic fingerprinting, oligonucleotide probes, etc. After the generation of probiotics, they are clinically tested to comprehend the health benefits they infer. Upon examination of the genetic functions of probiotics, it was concluded that these are utilized for the therapy of several diseases and disorders like- diarrhoea, allergies, metabolic, liver, and intestinal diseases. It also infers various health benefits likeheightened levels of glutathione reductase, enhancement in intestinal habits, increased mucosal Immunoglbin A antibodies, etc. The existing literature aimed to re-examine the sources, isolation methodology, characterization, and evaluation of probiotic strains by performing a literature analysis after summarising a sum of 1500 tasks and aimed to present a classical context and the status of this field.

\section{Isolation and Characterization of Lactobacillus Probiotic from Mother's Milk}

The study aimed to assess the probiotic characteristics of Lactobacillus strains isolated from the milk of their mother. It also assessed to see their influences on the assimilation of cholesterol. Cholesterol plays a significant role in the body as it is required for the production of cell membranes, insulation of nerves, production of hormones, and also affects human cardiovascular pathogenesis. The elevated cholesterol level in the body can cause some severe diseases. To alleviate this approach, probiotics- nonpathogenic micro-organisms, are used. They confer special health benefits to the host's body. The most common probiotics used in the health industry are- Lactic acid bacteria. The milk from a mother acts as a potential source for these probiotics, but their isolation was not performed.
In the given work, a total of 120 isolates were obtained from mother's milk and characterization of their phenotype and genotype was done. 6 out of 120 strains were identified as the species of Lactobacillus which were further analysed and assessed. The various parameters elected as test variables in the survival trials of stomach passage wereantimicrobial activity, acid and bile tolerance, cholesterol reduction, and antibiotic susceptibility. Considerable variations were explicated in the results. HMI68 strain showed maximum tolerance with acids while HMI74 and HMI28 strains exhibited maximum sensitivity. Tolerance to bile concentration was displayed by the HMI68 and HMI43 strains after 5 hours, while the HMI118 strain resisted growth at $0.5 \%$ and $1 \%$ bile concentration though, insignificant growth rates were obtained. The highest resistance to antibiotics and highest antagonistic activity were shown by the HMI68 strain. Bile salts increase the measure of reduction in cholesterol. Through 16S rRNA sequencing, HMI68 was recognized to be Lactobacillus oris HMI68. It was deposited in GenBank or National Center for Biotechnological Information where it was regarded as a potential probiotic. The investigation of the Lactobacillus isolated from the mother's milk and their cholesterolreducing property was analysed for the first time through this work.

Isolation and selection of strains of Saccharomyces cerevisiae from Food Source for use as Probiotic

"Probiotic is usually used to define live micro-organisms employed as food or pharmaceutical supplements that benefit human or animal health". Since probiotics are now being defined at a clinical level, they have been attracting interest and attention of customers due to their health benefits. Saccharomyces cerevisiae despite being demonstrated as an integral part of the microflora of many food products, its use as a probiotic is still limited. S.cerevisiae has been reported to cure recurrent diarrhoea cause by Clostridium difficile, thus proving its ability to control pathogenic microorganisms. The yeast strains isolated from common food were passed through simulations of human GI track with 5 strains effectively surviving and proving to be a suitable candidates to be used as components of probiotics. They were identifified as group-species C. parapsilosis/metapsilosis (3 strains), and one each for $C$. pararugosa and Pichia galeiformis/ membrane ifaciens/manshurica.

The survival of any probiotic in the human GI track is dependant on its ability to survive under effect of high $\mathrm{pH}$ and bile salt activity. The barriers that the have to break through are the gastric juices at the stomach, the intestinal juices as well as the peristaltic movements. Similar environments were created with the help of chemicals and centrifugation to conduct In-Vitro studies. After the first round of passing the food through the GI track, 22 isolates were found to be able to survive the gastrointestinal juices as a whole foods. These 22 were then plated in higher $\mathrm{pH}$ 
surroundings where all of the strains except A3 and D1 showed more than $90 \%$ survival rates. Next these were then passed through simulations of the physical movements in the GI track only 10 strains (B3, C1, C2, C3, D2, D3, G2, $\mathrm{G} 3, \mathrm{H} 2, \mathrm{H} 3$ ) showed more than $70 \%$ survival rates, these strains were then considered for further enzymatic reactions. All the enzymatic reactions showed that the selected yeast strains showed good lipolytic and proteolytic activities.

Out of all the 10 strains 5 strains, B3, D2, D3, H2 and H3 showed excellent hydrolysis of natural glucosidases and influencing food flavour. "Considering the molecular identification test 3 yeast strains with the best probiotic performance belonged to C. parapsilosis/metapsilosis (C2 and C3) and Pichia galeiformis membrane ifaciens manshurica (G3)". Thus, based on all the tests 5 strains of S.cerevisiae were selected three as Candida spp., one as Candida pararugosa and one as Pichia spp. "The Saccharomyces cerevisiae strains showed considerable probiotic properties, achieving a $80<\%<90$ survival through the simulated gastrointestinal tract, as well as interesting glucosidase activities."

Table 1 Origin of yeast strains isolated after screening for survival capability in simulated gastric and intestinal fluids

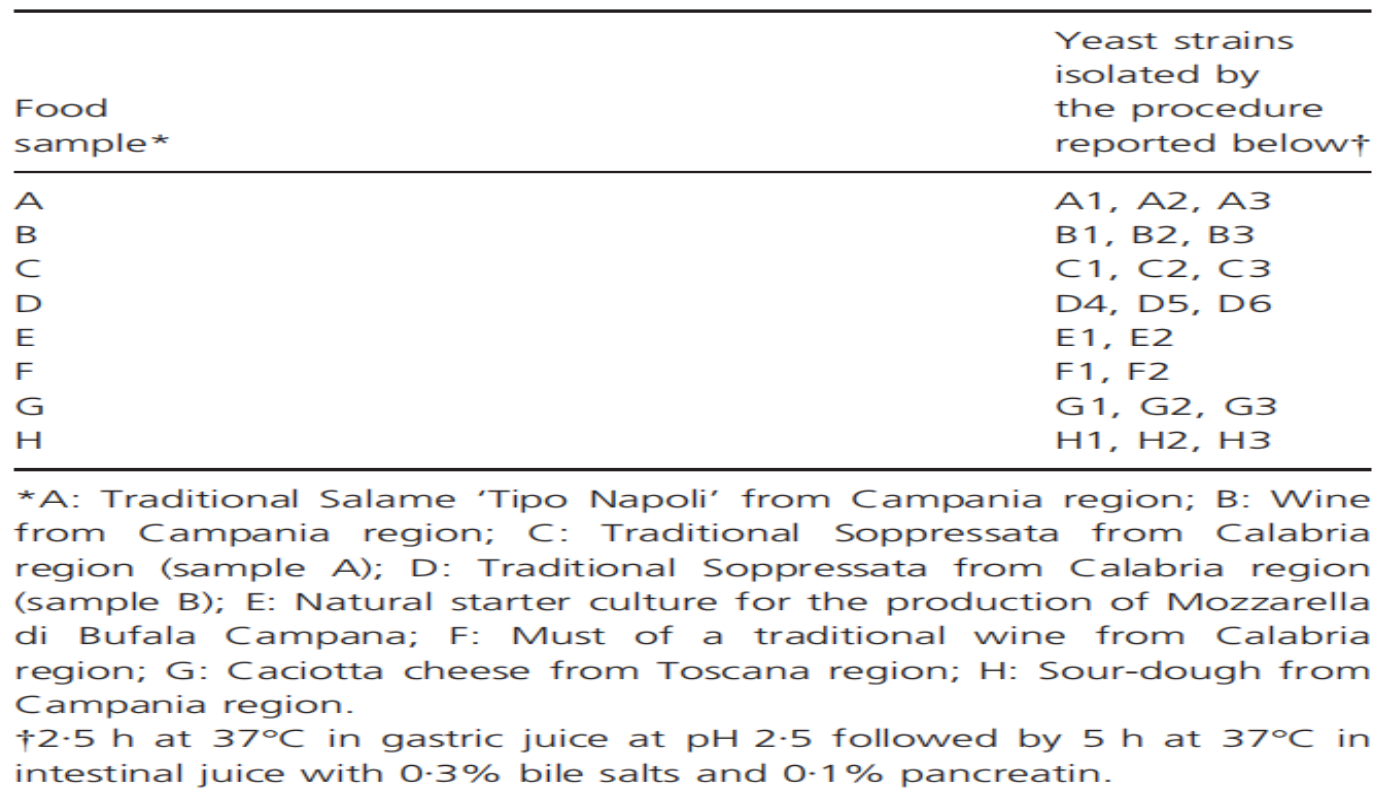

\section{Isolation of Actinomycetes as potential probiotics for aquaculture}

With increasing human consumption of crustaceans and mollusks, there has been an increasing risk of outbreaks of epidemics due to the development of resistance to antibiotics. To reduce the risk of disease outbreaks there has been a demand in use of probiotics in aquaculture. Their use ensures the development of no antibiotic resistance as probiotics work to develop self-immunity. Actinomycetes are producers of secondary metabolites they secrete a good amount of extracellular enzymes. After a series of in-vitro tests the strains Streptomyces panacagri and Streptomyces flocculus are found to be the closest to the actinomyctales order and have the same working as it.

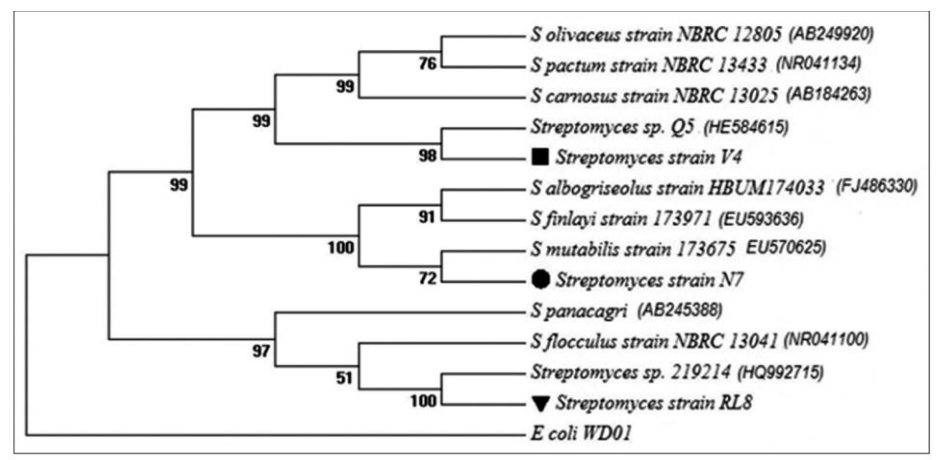

Figure-2: Phylogenetic tree derived from 16S rRNA gene sequences of potential probiotics and their closely related species. Numbers at nodes indicate the level (\%) of bootstrap support based on neighbour-joining analysis of 1000 re-sampled datasets. 


\section{Isolation of Probiotics from Dairy Products and their Characterisation}

The alive microorganisms that manifest advantageous health influences in the body of the host, upon their adequate ingestion are called probiotics. The two and the most important and common groups of Lactic acid bacteria used as probiotics are-Lactobacillus and Enterococcus species. These two bacterial species are Gram-negative and free from toxins. The Lactic acid bacteria can be isolated and distinguished from conventional dairy origins. They are acknowledged as innoxious microorganisms and thus, can be isolated from safe sources like- fermented dairy products and further be employed as probiotics. The given study intended at isolating and characterizing the strains of Lactic acid bacteria from traditional dairy products of Iran. These products have numerous health-enhancing advantages likeenhancement of nutrient consumption, inactivation of toxins, and anti-pathogenic actions and thus, are used comprehensively. They also impair the bioavailability of nutrients in the human body by aiding the consumption of magnesium and calcium from various milk proteins, ingesting lactose, and manufacturing folate and B vitamins. The classification .of these micro-organisms could not be done by conventional phenotyping and biochemical methods like- sugar fermentation because the growth of these bacteria occurs under comparable circumstances and these procedures failed to render outcomes that were precisely classified. Therefore, in the given study conventional dairy commodities of the west of Iran micro biota were screened to circumscribe innovative strains with a large probiotic inclination and their morphological and biochemical assays were operated by three molecular methods, specifically- REP-PCR (GTG-PCR), 16S rDNA sequencing, and ARDRA. In this research, an entirety of 19 LAB strains was distinguished which pertained to a total of 4 genera, specifically-Lactobacillus, Lactococcus, Leuconostoc, and Enterococcus. The inspections exhibited that the two strains of bacteria isolated from the shiraz- $L$. plantarum $15 \mathrm{HN}$ and $E$. mundtii $50 \mathrm{H}$ strains, and one strain isolated from cheese- $L$. lactis subsp. cremoris $44 \mathrm{~L}$ demonstrated an alluring susceptibility to various conditions like- low $\mathrm{pH}$ and raised bile salts, desirable antipathogen actions, and adequate antibiotic susceptivity. Therefore, it was stated that they could be acknowledged as innovative probiotic claimants and thus, should be practiced in the food enterprise.

\section{The effect of nitrate and probiotic addition in donors with different nitrate reduction capacities}

When growing in vitro biofilms with the saliva of donor D11 in the presence of nitrate, nitrate did not decrease compared to the baseline, and virtually no nitrite was produced, showing that the oral microbiota of this donor had a dramatically low NRC. However, a large percentage of nitrate was reduced when adding any of the isolates and the concentration of nitrite also increased notably. This indicates that the addition of a probiotic was able to compensate for the lack of NRC in this donor. When the same experiment was performed with the saliva of donors D5, D9, and D13, all added nitrate was reduced after $7 \mathrm{~h}$, even in the absence of isolates. This suggests that these donors have a high NRC and the addition of nitrate alone is enough to promote nitrate reduction. "

\section{Isolation of Weissella strains as Probiotics to Improve Antioxidant Activity of Fermented Squid.}

Ojingeojeot or fermented, salted squid is one of the highly consumed forms of seafood products in Korea. It is known to have high anticancer properties. Fermented foods are said to contain many enrichment substrates like vitamins, essential amino acids, bioactive compound, improvement of nutrient and inhibition of pathogen. They are known to have health-promoting, anti-aging, anti-carcinogenic, and antiobesity activities. Commonly LAB is one of the most common form of probiotic but in fermented squid there are various other bacterial strains present like Bacillus, Staphylococcus, Weissella, Carnobacterium, Leuconostoc and Pediococcus. The Weissella strain isolated from ojingeojeot is said to have "resistance to gastrointestinal tract and bile juice with antimicrobial activity to Listeria monocytogenes." In this experiment "Weissella spp. isolated from the traditional salted squid was screened for their probiotics properties such as resistance to the gastrointestinal tract, antibiotic resistance, and their abilities of auto-aggregation and co-aggregation". W. cibaria FB069 and $W$. viridescens FB-077 are found to have the potential to enhanced health benefits hence be used as probiotics.

Table 1 Antimicrobial activity of cell free supernatant broth of isolates against common pathogens, antibiotic resistance (MIC) and safety assessment

\begin{tabular}{|c|c|c|c|c|c|c|c|}
\hline & & FB069 & FB077 & & & FB069 & FB077 \\
\hline \multirow{9}{*}{$\begin{array}{c}\text { Pathogenic } \\
\text { strains }\end{array}$} & B. cereus & + & + & \multirow{6}{*}{ MIC $(\mu \mathrm{g} / \mathrm{mL})$} & Penicillin & 4 & 4 \\
\hline & E. coli $\mathrm{K} 99$ & + & ++ & & Ampicillin & 0.5 & 0.5 \\
\hline & L. monocytogenes & + & ++ & & Vancomycin & 64 & 128 \\
\hline & $S$. Gallinarum & ++ & ++ & & Streptomycin & 8 & 8 \\
\hline & S. aureus & + & + & & Kanamycin & 128 & 128 \\
\hline & $S$. Choleraesuis & + & ++ & & Tetracycline & 32 & 32 \\
\hline & $S$. Typhi & + & ++ & \multicolumn{2}{|c|}{ Bioamine production } & ND & ND \\
\hline & S. boydii & + & ++ & \multicolumn{2}{|c|}{ Hemolytic activity } & ND & ND \\
\hline & Y. enterocolitica & + & + & \multicolumn{2}{|c|}{ Mucin degradation } & ND & ND \\
\hline
\end{tabular}

+: $4 \mathrm{~mm}$;+: $8 \mathrm{~mm}$; ++: zone $>8 \mathrm{~mm}$

ND: non-detected 


\section{Conclusion:}

This research review's purpose is to help the reader understand different aspects posed by the research on the isolation and production of probiotics. This is significant because it gives insights about microencapsulation, Bacteriocin production, Aquaculture Probiotics, Yeast production, Anti-oxidant Probiotic from squid production. There has been much research and discussion conducted on these opinions on isolation and productions of microbes that can be used as probiotics. Most of the research found was on the details of subtopics and Keywords. More research and testing is required to gain a better understanding of the isolation and production of probiotics.

\section{Acknowledgement:}

We would like to thank our supervisor/guide Bharat Kwatra, from Invenzion Labs Inc. whose expertise was invaluable in formulating the research questions, methodology and drawing conclusions. His insightful feedback and guidance pushed us to sharpen our thinking and brought our work to a higher level.

6. Ethics approval and consent to participate: Not applicable.

7. Human and animal rights: No Animals/Humans were used for studies that are base of this research.

\section{Consent for publication: Not applicable.}

9. Availability of data and materials: The author confirms that the data supporting the findings of this research are available within the article.

\section{Funding acknowledgement and conflict of interest}

The authors whose names are listed immediately above certify that they have NO affiliations with or involvement in any organization or entity with any financial interest (such as honoraria; educational grants; participation in speakers' bureaus; membership, employment, consultancies, stock ownership, or other equity interest; and expert testimony or patent-licensing arrangements), or nonfinancial interest (such as personal or professional relationships, affiliations, knowledge or beliefs) in the subject matter or materials discussed in this manuscript.

\section{References}

1. Kwatra B, Zafar J, Choudhary M, Akhtar N, Golani T. ANALEPTIC APPLICATIONS OF PEPTIDES.

2. Kwatra B, Mudgil M. Finding Closely Related Organisms to Homo sapiens Insulin; Using Computational Biology.

3. Kwatra B. A review on Potential properties and therapeutic Applications of Carrots and Their Seed Extracts.

4. Kailasapathy K. Microencapsulation of probiotic bacteria: Technology and potential applications. Curr Issues Intest Microbiol. 2002;3(2).
5. Temmerman R, Pot B, Huys G, Swings J. Identification and antibiotic susceptibility of bacterial isolates from probiotic products. Int J Food Microbiol. 2003;81(1).

6. Temmerman R, Scheirlinck I, Huys G, Swings J. Culture-independent analysis of probiotic products by denaturing gradient gel electrophoresis. Appl Environ Microbiol. 2003;69(1).

7. Sakata T, Kojima T, Fujieda M, Takahashi M, Michibata T. Influences of probiotic bacteria on organic acid production by pig caecal bacteria in vitro. Proc Nutr Soc. 2003;62(1).

8. Pedersen C, Jonsson H, Lindberg JE, Roos S. Microbiological Characterization of Wet Wheat Distillers' Grain, with Focus on Isolation of Lactobacilli with Potential as Probiotics. Appl Environ Microbiol. 2004;70(3):1522-7.

9. Harish K, Varghese T. Probiotics in humansevidence based review. Calicut Med J. 2006;4(4).

10. Vélez MP, Hermans K, Verhoeven TLA, Lebeer SE, Vanderleyden J, Keersmaecker SCJ De. Identification and characterization of starter lactic acid bacteria and probiotics from Columbian dairy products. J Appl Microbiol. 2007;103(3).

11. ad Corr SC, Li Y, Riedel CU, O PW, Hill C, Gahan CGM. Bacteriocin production as a mechanism for the antiinfective activity of Lactobacillus salivarius UCC118 [Internet]. 2007. Available from: www.pnas.org/cgi/content/full/

12. Ramlucken U, Ramchuran SO, Moonsamy G, van Rensburg CJ, Thantsha MS, Lalloo R, et al. Bacteriocin production as a mechanism for the antiinfective activity of Lactobacillus salivarius UCC118. Proc Nutr Soc [Internet]. 2007;78(1). Available from: www.pnas.org/cgi/content/full/

13. Pennacchia C, Blaiotta G, Pepe O, Villani F. Isolation of Saccharomyces cerevisiae strains from different food matrices and their preliminary selection for a potential use as probiotics. J Appl Microbiol. 2008;105(6):1919-28.

14. Aly SM, Abd-El-Rahman AM, John G, Mohamed MF. Characterization of Some Bacteria Isolated from Oreochromis niloticus and their Potential Use as Probiotics. Aquaculture. 2008;277(1-2).

15. Wang YB, Li JR, Lin J. Probiotics in aquaculture: Challenges and outlook. Vol. 281, Aquaculture. 2008.

16. Pennacchia C, Blaiotta G, Pepe O, Villani F. Isolation of Saccharomyces cerevisiae strains from different food matrices and their preliminary selection for a potential use as probiotics. J Appl Microbiol. 2008;105(6).

17. Dobson A, Cotter PD, Ross RP, Hill C. Bacteriocin production: A probiotic trait? Vol. 78, Applied and Environmental Microbiology. 2012.

18. Fontana L, Bermudez-Brito M, Plaza-Diaz J, Muñoz-Quezada S, Gil A. Sources, isolation, characterisation and evaluation of probiotics. $\mathrm{Br} \mathrm{J}$ 
Nutr. 2013;109(SUPPL. 2).

19. Toscano M, de Vecchi E, Rodighiero V, Drago L. Microbiological and genetic identification of some probiotics proposed for medical use in 2011. J Chemother. 2013;25(3).

20. Fontana L, Bermudez-Brito M, Plaza-Diaz J, Muñoz-Quezada S, Gil A. Sources, isolation, characterisation and evaluation of probiotics. $\mathrm{Br} \mathrm{J}$ Nutr. 2013;109(SUPPL. 2).

21. Anandharaj M, Sivasankari B. Isolation of potential probiotic Lactobacillus oris HMI68 from mother's milk with cholesterol-reducing property. J Biosci Bioeng. 2014;118(2):153-9.

22. Mansour NM, Heine H, Abdou SM, Shenana ME, Zakaria MK, El-Diwany A. Isolation of Enterococcus faecium NM113, Enterococcus faecium NM213 and Lactobacillus casei NM512 as novel probiotics with immunomodulatory properties. Microbiol Immunol. 2014;58(10):559-69.

23. Lavari L, Páez R, Cuatrin A, Reinheimer J, Vinderola G. Use of cheese whey for biomass production and spray drying of probiotic lactobacilli. J Dairy Res. 2014;81(3).

24. Swain MR, Anandharaj M, Ray RC, Rani RP. Fermented Fruits and Vegetables of Asia: A Potential Source of Probiotics. Biotechnol Res Int. 2014;2014.

25. Berna MG, ángel Isidro Campa-Córdova, Saucedo PE, González MC, Marrero RM, Mazón-Suástegui JM. Isolation and in vitro selection of actinomycetes strains as potential probiotics for aquaculture. Vet World. 2015;8(2):170-6.

26. Haghshenas B, Nami Y, Abdullah N, Radiah D, Rosli R, Barzegari A, et al. Potentially probiotic acetic acid bacteria isolation and identification from traditional dairies microbiota. Int $\mathrm{J}$ Food Sci Technol. 2015;50(4).

27. Hai N V. The use of probiotics in aquaculture. Vol. 119, Journal of Applied Microbiology. 2015.

28. Haghshenas B, Nami Y, Almasi A, Abdullah N. Isolation and characterization of probiotics from dairies Separation of biactive peptides from tilapia by-product using membrane processes View project Vaccinology View project [Internet]. Article in Iranian Journal of Microbiology. 2017. Available from:

https://www.researchgate.net/publication/321679330

29. Othman M, Ariff AB, Wasoh H, Kapri MR, Halim M. Strategies for improving production performance of probiotic Pediococcus acidilactici viable cell by overcoming lactic acid inhibition. AMB Express. 2017;7(1).

30. Kwatra B. LOCATOR THEORY FOR ELEMENTS IN PERIODIC TABLE "LEPT." Glob J Pure Appl Chem Res. 2017;5(1):9-10.

31. Kwatra B. HACKING THE BLOOD-BRAIN BARRIER. Eur J Biol Med Sci Res. 2017;5(4):10-3.

32. Kwatra B. Tinospora Crispa As A Future Cure For
Obesity/Cholesterol. Int J Sci I\& Technol Res. 2017;6(7):340-1.

33. Le B, Yang SH. Isolation of weissella strains as potent probiotics to improve antioxidant activity of salted squid by fermentation. J Appl Biol Chem. 2018;61(1):93-100.

34. Arshad F-A, Mehmood R, Hussain S, Khan MA, Khan MS. Lactobacilli as Probiotics and their Isolation from Different Sources. $\mathrm{Br} \quad \mathrm{J}$ Res. 2018;05(03).

35. Masalam MS Bin, Bahieldin A, Alharbi MG, AlMasaudi S, Al-Jaouni SK, Harakeh SM, et al. Isolation, Molecular Characterization and Probiotic Potential of Lactic Acid Bacteria in Saudi Raw and Fermented Milk. Evidence-based Complement Altern Med. 2018;2018.

36. Wanka KM, Damerau T, Costas B, Krueger A, Schulz C, Wuertz S. Isolation and characterization of native probiotics for fish farming. BMC Microbiol. 2018;18.

37. Prabina BJ, Kumutha K, Anandham R, Durga P. Isolation and Characterization of Multifunctional Yeast as Plant Probiotics for Better Crop Nutrition in Pulses. Int $\mathbf{J}$ Curr Microbiol Appl Sci. 2019;8(01):2711-8.

38. Reuben RC, Roy PC, Sarkar SL, Alam RU, Jahid IK. Isolation, characterization, and assessment of lactic acid bacteria toward their selection as poultry probiotics. BMC Microbiol. 2019;19(1).

39. Angelescu IR, Zamfir M, Stancu MM, Grosu-Tudor SS. Identification and probiotic properties of lactobacilli isolated from two different fermented beverages. Ann Microbiol. 2019;69(13).

40. Chandel D, Sharma M, Chawla V, Sachdeva N, Shukla G. Isolation, characterization and identification of antigenotoxic and anticancerous indigenous probiotics and their prophylactic potential in experimental colon carcinogenesis. Sci Rep. 2019;9(1).

41. Fenster K, Freeburg B, Hollard C, Wong C, Laursen $\mathrm{RR}$, Ouwehand AC. The production and delivery of probiotics: A review of a practical approach. Microorganisms. 2019;7(3).

42. Kwatra B, Mudgil M. PROTONATED CRAB SHELL WASTE AS FUNGAL INHIBITOR. Int J Med Biomed Stud. 2019;3(4):111-6.

43. Kwatra B. HYDROQUINONE: A novel growth inhibitor and apoptosis inducer in U-251 MG CELLS. Int J Med Biomed Stud. 2019;3(6):15-6.

44. Kwatra B. EXPRESSION AND CHARACTERIZATION IN PICHIA PASTORIS BY CLONING OF DELTA 4 DESATURASE FROM ISOCHRYSIS GALBANA. Indian J Appl Res. 2019;9(5):1-2.

45. Kwatra B. A REVIEW ON POTENTIAL PROPERTIES AND THERAPEUTIC APPLICATIONS OF BROMELAIN. WORLD J Pharm Pharm Sci. 2019;8(11):488-500. 
46. Kwatra B. CALCIUM AND IRON ABSORPTION: INVITRO STUDIES. Int $\mathrm{J}$ Med Biomed Stud. 2019;3(12):59-61.

47. Kwatra B. Effects of Mineral Separation by Time and Enteric Coating Mechanism for Calcium and Iron Absorption in Mammalia. Int $\mathrm{J}$ Sci Res. 2019;8(12):1265-70.

48. Bharat Kwatra CA. Mathematical and Statistical Approach to Define Past Present Future Events. Vol. 8, International Journal of Science and Research (IJSR). International Journal of Science and Research (IJSR); 2019. p. 260-3.

49. Kwatra B. A Review on Potential Properties and Therapeutic Applications of DHA and EPA. Int J Pharm Pharm Sci. 2019;16(4):140-76.

50. Kwatra B. Bioactive-Compounds: an alternative to control Candida spp. Int J Sci Res Rev. 2019;8(9):221-3.

51. Kwatra B. Holothuroidea (Sea Cucumber): Key to Anti-Aging. Int J Sci Res. 2019;8(6):884.

52. Kwatra B. Procuring Natural Dye for Solar Cell Using Leaf Waste. Int J Sci Res. 2019;7(5):46-7.

53. Kwatra B. Allicin -An After Digestion Antimicrobial Agent. ACTA Sci Microbiol. 2019;2(5):48-51.

54. Kwatra B. MECHANISMS OF PATTERN FORMATION OF FBP17 IN MAST CELLS. Int J Adv Res. 2019;7(4):413-4.

55. Bharat Kwatra MM. Mosquito Menace. Int J Sci Res. 2019;8(1):1314-5.

56. Kwatra B. Studies on People Employed in High Risk Workplace: Between Genetic Polymorphism for Tumor Necrosis Factor (TNF-A) and Blood Pressure. J Pharm Pharm Sci. 2019;8:488-500.

57. Mudgil M, Kwatra B. Mosquito Menace Aim: Observing the life cycle of Aedes aegypti mosquito and understanding its behavior towards different natural oils for encouraging natural methods of repellence. Int J Sci Res. 2019;8:1314-5.

58. Bharat Kwatra MM. Untangling the Mathematical Relation Between Natural Selection and Adaptive Radiation Using Macromolecules and Microevolutionary Forces. Int J Res Sci Technol. 2020;7(2):313-39.

59. Kwatra B. Maprovit 3, 6, 9: Perfect Companion of your Immune System to Fight Corona Virus Hit. Int J Sci Res. 2020;9(4):241.

60. Kwatra B. A Review on Potential Properties and Therapeutic Applications of Vitamin D. Int J Sci Res. 2020;9(4):682-91.

61. Kwatra B, Mudgil M. LIGHT ASSISTED TIO2BASED NANOCOMPOSITE SYSTEMS: A NOVEL TREATMENT FOR CANCER. Int J Med Biomed Stud. 2020;4(4):28-32.

62. Bharat Kwatra CA. THE UNEXPLAINED SIMILARITY BETWEEN THE ATOMIC AND GRAVITATIONAL MODELS. Int $\mathrm{J}$ Adv Res. 2020;8(3):1099-107.
63. Kwatra B. A REVIEW ON POTENTIAL PROPERTIES AND THERAPEUTIC APPLICATIONS OF LYCOPENE. Int $\mathrm{J}$ Med Biomed Sci. 2020;4(4):33-44.

64. Kwatra B. A REVIEW ON POTENTIAL PROPERTIES AND THERAPEUTIC APPLICATIONS OF BRANCHED CHAIN AMINO ACIDS. WORLD J Pharm Pharm Sci. 2020;9(5):561-88.

65. Bharat Kwatra CA. Studying the movements of the resonant elastic pendulum. Indian $\mathrm{J}$ Appl Res. 2020;10(5):1-2.

66. Kwatra B. COLLAGEN SUPPLEMENTATION: THERAPY FOR THE PREVENTION AND TREATMENT OF OSTEOPOROSIS AND OSTEOARTHRITIS: A REVIEW. WORLD J Pharm Pharm Sci. 2020;10(5):589-604.

67. Kwatra B. A REVIEW ON POTENTIAL PROPERTIES AND THERAPEUTIC APPLICATIONS OF GRAPE SEED EXTRACT. World J Pharm Res. 2020;9(5):2519-40.

68. Kwatra B. COLLAGEN SUPPLEMENTATION: THERAPY FOR SKIN DISORDERS: A REVIEW. World J Pharm Res. 2020;9(5):2504-18.

69. Kwatra B, Arora C. Investigation of Conductance Quantization with Magnetic Field Control and Application of Biosensor. Int J Innov Res Technol. 2020;6(12):271-2.

70. Kwatra B. Candidate genes of OCD interacts with human retrovirus to form new link in inflammatory hypothesis. Int J Sci \\& Appl Res. 2020;7(5):1-2.

71. Kwatra B. UTERINE CANCER: SEX DOMINANT CHARACTER. Int J Adv Res. 2020;8(4):663-7.

72. Kwatra B, Modi R. Therapeutic Potentials and Applications of Folic Acid and Beta Carotene. Int J Sci Res Sci Technol. 2020;7(4):271-82.

73. Kwatra B, Hussain MS, Bhowmik R, Manoharan S. Reviewing Therapeutic and Immuno-Pathological Applications of Vitamins and Carotenoids. Int J Sci Res Sci Technol. 2020;7(4):287-313.

74. Kwatra B, Ega G, Mishra G, Jain A. THERAPEUTIC APPLICATIONS OF VITAMINS AND PIGMENTS IN RESPIRATORY DISORDERS. 2020;

75. Kwatra B, Mir AM, Salagundi R, Khair S. Therapeutic and Clinical applications of Ginseng, Curcumin and Allicin. Int $\mathbf{J}$ Creat Res. 2020;8(8):3113-24.

76. Kwatra B, Arora C. The Studying Of Movements Resonant the Pendulum Elastic. Indian J Appl Res. 2020;10:1-2.

77. Kwatra B, Agarwal R. Misfolded Proteins in Parkinson's and Alzheimer Disease: A Review. 2020;

78. Rosier BT, Moya-Gonzalvez EM, Corell-Escuin P, Mira A. Isolation and Characterization of NitrateReducing Bacteria as Potential Probiotics for Oral and Systemic Health. Front Microbiol. 2020;11. 
79. Labba ICM, Andlid T, Lindgren $\AA$, Sandberg AS, Sjöberg F. Isolation, identification, and selection of strains as candidate probiotics and starters for fermentation of swedish legumes. Food Nutr Res. 2020;64:1-13.

80. Guan C, Tao Z, Wang L, Zhao R, Chen X, Huang X, et al. Isolation of novel Lactobacillus with lipolytic activity from the vinasse and their preliminary potential using as probiotics. AMB Express. 2020;10(1).

81. Ramlucken U, Ramchuran SO, Moonsamy G, van
Rensburg CJ, Thantsha MS, Lalloo R. Production and stability of a multi-strain Bacillus based probiotic product for commercial use in poultry. Biotechnol Reports. 2021;29.

82. Bharat K, Ratna R, Ratul B, Sounok S. DRUG REPURPOSING: IN SILICO MODELING OF COVID-19. Res J Pharm Biol. 2021;7(2):19-40.

83. Kwatra B, Khatun A, Bhowmik R, Rehman S. In silico-modelling of phytochemicals in septic arthritis. 2021; 